\title{
Physiology and proteomics of two maize genotypes with different drought resistance
}

\author{
Y.H. LI ${ }^{1,2}$, J.Y. CUI ${ }^{1}$, Q. ZHAO ${ }^{2}$, Y.Z. YANG ${ }^{2}$, L. WEI ${ }^{1}$, M.D. YANG ${ }^{1}$, F. LIANG ${ }^{2}$, S.T. DING ${ }^{2}$, \\ and T.C. WANG ${ }^{1 *}$ \\ Collaborative Innovation Center of Henan Grain Crops, Agronomy College of Henan Agricultural University, \\ Zhengzhou, 450002, Henan, P.R. China ${ }^{1}$ \\ College of Life Sciences, Zhengzhou Normal University, Zhengzhou 450044, Henan, P.R. China ${ }^{2}$
}

\begin{abstract}
The aim of this study was to investigate the physiological basis and molecular mechanism of genotypic variation in drought response of maize seedlings. Comparative physiological and proteomic analyses were conducted in the leaves of droughttolerant Liyu 35 (LY) and drought-sensitive Denghai 605 (DH) maize genotype seedlings. Drought induced a significant decrease of relative water content and osmotic potential of leaves, length and volume of roots, and total dry weight, but significantly increased malondialdehyde in DH seedlings. However, root dry weight, proline content and antioxidant enzyme activities increased more in LY than in DH. Forty-two spots in LY and 17 spots in DH that showed significant abundance variations were identified by matrix-assisted laser desorption/ionization time-of-flight/time-of-flight mass spectrometry. These drought-responsive proteins were mainly involved in biological processes of photosynthesis, defense and oxidative stress, carbohydrate and energy metabolism, protein synthesis and processing, and cell wall biogenesis and degradation. Among them, proteins involved in defense and oxidative stress, and protein synthesis and processing were largely enriched in the LY genotype, which may contribute to a natural variation of drought resistance between LY and DH genotypes. The altered protein abundance and corresponding physiological-biochemical response shed some light on molecular mechanisms related to drought tolerance in drought-tolerant maize and provide key candidate proteins for genetic improvement of maize.
\end{abstract}

Additional key words: maize, drought stress, relative water content, reactive oxygen species, proteomics, drought-responsive protein.

\section{Introduction}

Drought is one major environmental stress factor that limits growing and productivity of many important crops around the world (Mahajan and Tuteja 2005). Particularly, a climate change and population growth pose a big challenge to crop improvement. The understanding of responses of crops to drought stress at the molecular level is helpful for improving drought-resistant genotypes (Ashraf 2010). Maize, one important crop in the world, is vulnerable to water-deficiency, especially during the flowering, pollination and embryonic phases (Boyer 2004).

Researches certify that drought stress impacts plant structure, metabolism and growing, which often shows the following symptoms: loss of turgor, stomata closure, moisture loss, low leaf water potential and slow cell elongation and growth (Farooq et al. 2009). Serious moisture loss may disrupt photosynthesis, energy production and metabolism, and eventually kill cells (Faghani et al. 2015). A slow leaf growth is one earliest

Submitted 29 August 2018, last revision 18 October 2018, accepted 8 January 2019.

Abbreviations: bGlu - endo-1,3-1,4-beta-D-glucanase; CBP - chlorophyll a/b binding protein; CYP - cyclophilin; 2-DE - two-dimensional gel electrophoresis; DH - Denghai 605; DRP - drought-responsive protein; DTT - ithiothreitol; DWR - root dry weight; DWS - shoot dry weight; EDTA - ethylene diamine tetraacetic acid; FBA - fructose-bisphosphate aldolase; FBP - fructose-1,6-bisphosphate; FC - field capacity; GAPDH - glyceraldehyde-3-phosphate dehydrogenases; GLP - germin-like protein; GST - glutathione-S-transferase; IEF isoelectric focusing; LY - Liyu 35; MALDI-TOF - matrix-assisted laser desorption/ionization time of flight; MDA - malondialdehyde; MS - mass spectrometry; NDPK - nucleoside diphosphate kinase; OEC - oxygen-evolving complex; OEE1 - oxygen-evolving enhancer protein 1; POD - peroxidase; PPI - peptidyl-prolyl cis-trans isomerase; PS - photosystem; RCA - RuBisCO activase; ROS - reactive oxygen species; RuBisCO - ribulose- 1,5-bisphosphate carboxylase/oxygenase; RWC - relative water content; SDS-PAGE - sodium dodecyl sulfate polyacrylamide gel electrophoresis; SOD - superoxide dismutase.

Acknowledgments: This study was supported by the National Natural Science Foundation of China (31471452), National Key Research and Development Program of China (2017YFD0301106), Foundation of Henan Postdoctoral Research Project (166880) and Foundation of Education Department of Henan Province (17B180007).

* Correspondence author; fax: 0371-63558122, e-mail:wtcwrn@126.com 
symptom of limited water availability, which may reduce transpiration and water conservation (Ribaut et al. 1997). Furthermore, at the molecular level, drought stress affects gene expression level of different pathways related to stress perception, signal transduction, regulators, and the synthesis of stress-related proteins (Kakumanu et al. 2012). Proteomic changes of many plants have been studied under drought stress, including wheat (Faghani et al. 2015), barley (Vítámvás et al. 2015), cotton (Deeba et al. 2012), tobacco (Xie et al. 2016), rapeseeds (Urban et al. 2016), peanut (Katam et al. 2016), grapevine (Król and Weidner 2017), and maize (Benesova et al. 2012, Hu et al. 2011, Liu et al. 2012). Studies of proteins in maize (Kakumanu et al. 2012) and wheat (Caruso et al. 2009) show that a very close relationship exists between drought resistance and gene expression.

As one important crop species, maize (Zea mays L.) is susceptible to even a mild or moderate drought stress, especially during the heading stage. At the beginning of growing, however, the shortage of soil water limits biomass production, affects the formation of reproductive organs and yield parameters (Mahajan and Tuteja 2005). Drought occurs at any growth stage, but water stress posseses the most adverse effect on yield at the heading stage. A previous research clarified mechanisms underlying drought stress at the transcriptional level (Kakumanu et al. 2012, Maheswari et al. 2016, Thatcher et al. 2016), and a large number of genes and gene products have been explored in drought response (Xu et al. 2014, Nuccio et al. 2015), but it is still unclear how the proteomes of different maize genotypes respond to drought stress. In this study, we aim to differentially detect abundant proteins to specifically identify those related to drought tolerance in two maize genotypes chosen based on sensitivity to an abiotic stressor at an early development stage. Twodimensional gel electrophoresis (2-DE)-based matrixassisted laser desorption/ionization (MALDI) time-offlight/time-of-flight (TOF/TOF) mass spectrometry (MS) proteomic analyses of two maize genotypes Liyu 35 (LY) and Denghai $605(\mathrm{DH})$ that show different tolerances to drought stress were performed. Additionally, physiological changes induced by the stress were measured for each genotype.

\section{Materials and methods}

Plants and treatments: Two maize (Zea mays L.) genotypes, drought-resistant Liyu 35 (LY) and droughtsensitive Denghai 605 (DH) were selected based on stress susceptibility and stress tolerance indices in the view of our earlier research. Seeds were purchased from the Henan Qiule Seeds Technology Co., Ltd. and sown in plastic culture pots filled with soil containing two different relative water content (RWC). The soil had a maximum of $22.67 \mathrm{~g}$ water per $100 \mathrm{~g}$ of dry weight at field capacity (FC) from the Science Park Experimental Base of Henan Agricultural University. The treatment was designed with two watering conditions and two genotypes in three replications during the early seedling stage. The control was maintained at
$75 \%$ of FC, while the drought stress was imposed by evapotranspiration until the soil water reached $40 \%$ of FC, and the volumetric soil water content was the same in both genotypes. The seeds were planted in plastic pots with each pot having 40 holes and containing 40 seeds. After sowing, the water in the control plants was maintained at $75 \%$ of FC, while the drought-stressed plants with holding water at $40 \%$ of FC by covering the pots with plastic sheeting. The growth conditions were controlled at $28{ }^{\circ} \mathrm{C}$ day $/ 25$ ${ }^{\circ} \mathrm{C}$ night, a $60 \%$ relative humidity, and $15 / 9 \mathrm{~h}$ day/night photoperiods in a growth chamber.

Measurement of morphological and physiological parameters: After one week, leaf samples were collected from the second leaf for leaf RWC and leaf osmotic potential determinations and immediately frozen in liquid nitrogen for physiological parameters and proteome analyses. The height of plants was measured by the distance from the soil level in pots to the tip of the youngest visible leaf in the top whorl of leaves, and the plants were cut at the stem base and oven-dried at $75^{\circ} \mathrm{C}$ for $24 \mathrm{~h}$ to measure shoot dry weight (DWS). To collect roots, seedlings were pulled out of the soil and roots were carefully washed to remove soil particles. Root length and volume were measured and then root samples were oven-dried $\left(75^{\circ} \mathrm{C}\right.$ for $24 \mathrm{~h}$ ) to measure root dry weight (DWR). Leaf RWC was measured according to the method of Faghani et al. (2015), and leaf osmotic potential was determined using a dew point microvoltmeter (Vapro-5520, Wescor, USA) as described by Chen et al. (2016).

The content of malondialdehyde (MDA) was measured according to Dipierro and Leonardis (1997) with some modifications. A leaf sample $(0.5 \mathrm{~g})$ was homogenized in $5 \mathrm{~cm}^{3}$ of $0.1 \%(\mathrm{~m} / \mathrm{v})$ trichloroacetic acid and then centrifuged at $12000 \mathrm{~g}$ for $20 \mathrm{~min}$. Then, $1 \mathrm{~cm}^{3}$ of the supernatant was mixed with $4 \mathrm{~cm}^{3}$ of a $0.5 \%(\mathrm{~m} / \mathrm{v})$ thiobarbituric acid solution and incubated in a boiling water bath for $30 \mathrm{~min}$. After cooling on ice, the mixture was centrifuged at $10000 \mathrm{~g}$ for $5 \mathrm{~min}$ and the supernatant was used for an MDA assay. Free proline content was assessed in fresh leaf samples using ninhydrin according to the method of Bates et al. (1973). A frozen leaf sample $(0.2 \mathrm{~g})$ was homogenized in $3 \mathrm{~cm}^{3}$ of ice-cold extraction buffer consisting of $50 \mathrm{mM}$ potassium phosphate, $\mathrm{pH} 7.8$, $0.1 \mathrm{mM}$ EDTA, and $1 \%(\mathrm{~m} / \mathrm{v})$ polyvinylpyrrolidone. The homogenate was centrifuged at $10000 \mathrm{~g}$ and $4{ }^{\circ} \mathrm{C}$ for $20 \mathrm{~min}$, and the supernatant was immediately used for enzyme activity assays. Total superoxide dismutase (SOD, EC 1.15.1.1) activity was assayed by monitoring the inhibition of photochemical reduction of nitroblue tetrazolium at $560 \mathrm{~nm}$ (Beauchamp and Fridovich 1971). One unit of SOD activity was defined as the amount of enzyme required to cause a $50 \%$ inhibition of the nitroblue tetrazolium reduction. Peroxidase (POD, EC1.11.1.7) activity was determined using the improved method of Hammerschmidt et al. (1982). extraction sample homogenate $\left(30 \mathrm{~mm}^{3}\right)$ was added into a $3 \mathrm{~cm}^{3}$ reaction solution $\left(1 \mathrm{dm}^{3}\right.$ of phosphate buffer solution $[0.2 \mathrm{M}$, $\mathrm{pH}=6.0]$ with $0.36 \mathrm{~cm}^{3}$ of guaiacol, and $0.506 \mathrm{~cm}^{3}$ of $30 \% \mathrm{H}_{2} \mathrm{O}_{2}$ ), and absorbance was read at $470 \mathrm{~nm}$ with a 
$30 \mathrm{~s}$ interval up to $2 \mathrm{~min}$ and used the absorbance change of 0.01 per min as a unit of POD activity.

The 2-DE analysis of leaf protein: Total soluble leaf proteins were extracted from three independent biological replicates in each treatment according to Wang et al. (2006) with minor modifications. The leaf tissue (1 g) was grounded into a fine powder in liquid nitrogen and extracted with ice-cold $10 \%(\mathrm{~m} / \mathrm{v})$ trichloroacetic acid in acetone. An air-dried protein pellet was dissolved in a 2-DE rehydration buffer [9.5 M Urea, $4 \%(\mathrm{~m} / \mathrm{v})$ CHAPS, $60 \mathrm{mM}$ DTT, $2 \%$ (v/v) ampholytes (pI 3-10, Bio-Lytes, BioRad, USA)], and to each $500 \mathrm{~mm}^{3}$ of the buffer, $10 \mathrm{~mm}^{3}$ of a protein inhibitor Cocktail Set I (Merck) was added before using. The protein samples were crushed with an ultrasonic crusher $(80 \mathrm{~W}$ for $10 \mathrm{~s}$, interruption for $15 \mathrm{~s}, 10$ times), and then centrifuged at $14000 \mathrm{~g}$ for $20 \mathrm{~min}$. The total protein concentration was determined by a Bio-Rad protein assay (Bio-Rad, Hercules, CA, USA) with bovine serum albumin as a standard.

Isoelectric focusing (IEF) was conducted by using $13 \mathrm{~cm}$ immobilized $\mathrm{pH}$ gradient strips (pH 3-10, nonlinear) in an Ettan IPG phor IEF System (GE Amersham) according to Wang et al. (2010) with some modifications. The IEF was performed as follows: $30 \mathrm{~V}$ for $12 \mathrm{~h}, 500 \mathrm{~V}$ for $1 \mathrm{~h}, 1000 \mathrm{~V}$ for $1 \mathrm{~h}$, and $8000 \mathrm{~V}$ for $8 \mathrm{~h}$. After IEF, the strips were equilibrated in buffer I $(50 \mathrm{mM}$ Tris- $\mathrm{HCl}, \mathrm{pH} 8.8,2 \%$ (m/v) SDS, $6 \mathrm{M}$ urea, $30 \%$ (v/v) glycerol, $1 \%(\mathrm{~m} / \mathrm{v})$ DTT) for $15 \mathrm{~min}$ and then for another $15 \mathrm{~min}$ in buffer II (its composition was the same as buffer I, but with $4 \%(\mathrm{~m} / \mathrm{v})$ iodoacetamide replacing DTT). The second dimension SDS-PAGE was run using a $12.5 \%$ $(\mathrm{m} / \mathrm{v})$ polyacrylamide gel in a vertical slab of Hofer $S E$ 600 (GE Amersham) at $15 \mathrm{~mA}$ per gel for $30 \mathrm{~min}$ followed by $30 \mathrm{~mA}$ per gel until bromophenol blue reached the end of the gel. The 2-DE gels were silver stained and the images were analyzed by the Image Master $2 D$ Platinum analysis software (Version 5.0, GE Amersham) to screen differentially expressed protein spots. Protein spots with 1.2-fold variations in abundance were subjected to MS for protein identification.

The selected protein spots were manually excised from the gel and digested with trypsin according to Wang et al. (2010). Mass spectrometry and MS/MS spectra were automatically performed using a MASCOT search engine 2.2 (Matrix Science, Ltd.) that was embedded into the GPS-Explorer Software 3.6 (Applied Biosystems) in the $N C B I$ database, and 279,566 sequences generated from protein sequences of Zea mays (downloaded February 2017). The other parameters were the enzyme trypsin, one missed cleavage, fixed modifications of carbamidomethyl, dynamical modifications of oxidation, peptide mass tolerance of $100 \mathrm{ppm}$, fragment mass tolerance of $\pm 0.4 \mathrm{Da}$, peptide charge of 1+. A GPS Explorer protein confidence interval $\geq 95 \%$ was used for further manual validation, and at least two-peptide matches were required for positive identifications.

Statistical analysis: Data were subjected to one-way analysis of variance using the SPSS 20.0 (SPSS, Chicago, USA), followed by Tukey-Kramer tests (with a probability level $<0.05$ treated as a statistically significant) for comparisons between individual genotype/water treatment combinations. Each datum point represents a mean of six replicates and is expressed as means \pm standard deviations (SDs).

\section{Results}

Drought stress significantly reduced plant height and total dry weight in comparison to controls in the two maize genotypes, but the parameter decreases were more obvious in DH (61.0\% and 51.4\%) compared with LY (37.3\% and

Table 1. The parameters of drought-tolerant Liyu 35 (LY) and drought-sensitive Denghai 605 (DH) maize genotypes measured under control (CK) and drought stress (DS) conditions. Means \pm SDs, $n=6$. Different letters denote significant differences between genotypes or water treatments $(P \leq 0.05)$. MDA - malondialdehyde, SOD - superoxide dismutase, POD - peroxidase.

\begin{tabular}{|c|c|c|c|c|}
\hline Parameter & DH-CK & DH-DS & LY-CK & LY-DS \\
\hline Plant height $[\mathrm{cm}]$ & $19.32 \pm 0.25 \mathrm{~b}$ & $7.53 \pm 1.04 \mathrm{~d}$ & $21.42 \pm 1.06 \mathrm{a}$ & $13.43 \pm 0.56 \mathrm{c}$ \\
\hline Total dry mass $\left[\mathrm{g} \mathrm{plant}^{-1}\right]$ & $0.14 \pm 0.01 \mathrm{a}$ & $0.07 \pm 0.01 \mathrm{c}$ & $0.11 \pm 0.01 \mathrm{~b}$ & $0.10 \pm 0.01 \mathrm{~b}$ \\
\hline RWC [\%] & $0.96 \pm 0.02 \mathrm{a}$ & $0.83 \pm 0.02 \mathrm{c}$ & $0.89 \pm 0.02 \mathrm{~b}$ & $0.81 \pm 0.01 \mathrm{c}$ \\
\hline Leaf osmotic potential [MPa] & $-0.99 \pm 0.01 \mathrm{~d}$ & $-1.43 \pm 0.07 \mathrm{a}$ & $-1.08 \pm 0.00 \mathrm{c}$ & $-1.28 \pm 0.02 b$ \\
\hline Root length [cm] & $17.98 \pm 1.38 \mathrm{~b}$ & $11.68 \pm 1.81 \mathrm{c}$ & $20.45 \pm 0.65 \mathrm{a}$ & $17.17 \pm 0.87 \mathrm{~b}$ \\
\hline Root volume $\left[\mathrm{cm}^{3}\right]$ & $0.73 \pm 0.05 b$ & $0.37 \pm 0.05 \mathrm{~d}$ & $0.83 \pm 0.08 \mathrm{a}$ & $0.55 \pm 0.05 \mathrm{c}$ \\
\hline Shoot dry mass [g plant $\left.{ }^{-1}\right]$ & $0.09 \pm 0.01 \mathrm{a}$ & $0.03 \pm 0.01 \mathrm{~d}$ & $0.07 \pm 0.01 \mathrm{~b}$ & $0.05 \pm 0.00 \mathrm{c}$ \\
\hline Root dry mass [g plant $\left.{ }^{-1}\right]$ & $0.05 \pm 0.01 \mathrm{a}$ & $0.03 \pm 0.01 \mathrm{~b}$ & $0.04 \pm 0.01 \mathrm{a}$ & $0.05 \pm 0.01 \mathrm{a}$ \\
\hline Root to shoot ratio & $0.57 \pm 0.05 \mathrm{c}$ & $1.10 \pm 0.17 \mathrm{~b}$ & $0.63 \pm 0.08 \mathrm{c}$ & $1.20 \pm 0.14 \mathrm{a}$ \\
\hline Rate of dry matter transformation & $0.50 \pm 0.05 \mathrm{a}$ & $0.27 \pm 0.07 \mathrm{~d}$ & $0.41 \pm 0.05 \mathrm{~b}$ & $0.34 \pm 0.04 \mathrm{c}$ \\
\hline MDA content $\left[\mu \mathrm{mol} \mathrm{g}{ }^{-1}(\right.$ f.m. $\left.)\right]$ & $7.80 \pm 0.71 \mathrm{~b}$ & $11.42 \pm 1.24 \mathrm{a}$ & $5.33 \pm 0.75 \mathrm{c}$ & $7.40 \pm 0.54 b$ \\
\hline Proline content $\left[\mu \mathrm{g} \mathrm{g}^{-1}(\mathrm{f} . \mathrm{m}).\right]$ & $17.00 \pm 0.75 \mathrm{c}$ & $22.21 \pm 1.66 \mathrm{~b}$ & $15.80 \pm 0.73 \mathrm{c}$ & $35.97 \pm 1.35 \mathrm{a}$ \\
\hline SOD activity $\left[\mathrm{U} \mathrm{g}^{-1}\right.$ (f.m.) $\left.\mathrm{min}^{-1}\right]$ & $264.00 \pm 12.6 \mathrm{a}$ & $186.24 \pm 16.9 \mathrm{a}$ & $165.68 \pm 23.3 \mathrm{c}$ & $207.58 \pm 8.87 b$ \\
\hline POD activity [ $\mathrm{U} \mathrm{g}^{-1}$ (f.m.)] & $3.80 \pm 0.15 \mathrm{a}$ & $3.92 \pm 0.26 \mathrm{a}$ & $3.00 \pm 0.10 \mathrm{c}$ & $3.45 \pm 0.07 \mathrm{~b}$ \\
\hline
\end{tabular}


$12.7 \%$, Table 1), respectively. Similarly, drought stress significantly reduced leaf RWC and leaf osmotic potential compared with controls in the two maize seedlings, but leaf RWC was reduced slightly greater in DH (13.54\%) compared with LY $(8.99 \%)$, and leaf osmotic potential was reduced more in DH (44.7\%) compared with LY (18.9\%). However, leaf RWC and leaf osmotic potential maintained at lower levels in LY than in DH under control conditions (Table 1).

Under control and stress conditions, the DH genotype produced shorter roots and a lower root volume (Table 1). As compared with the control, the parameter decreased more in DH (35.0 \% and $49.3 \%)$ than in LY $(16.0 \%$ and $33.7 \%$ ), respectively. Similarly, the plants subject to drought stress also reflected lower DWS and the rate of dry matter transformation when compared with the control; the parameter decreases were more obvious in DH (66.3 \% and $46.0 \%)$ compared with LY $(33.8 \%$ and $17.1 \%$ ), respectively. With regard to DWR, the value of this parameter in the roots of DH significantly decreased (62.7 \% of the control), whereas a statistically significant increase ( $129 \%$ of the control) in this parameter was observed in LY. A marked increase in the ratio of root to shoot due to drought stress was observed in both the genotypes (184\% of the control in DH and $190 \%$ of the control in LY).

Drought stress caused MDA content increased by $46.4 \%$ and $38.8 \%$ in DH and LY, respectively, but it was much higher in DH than in LY (Table 1). Under control conditions, DH and LY leaves had a similar proline content, but content increased under drought stress. It increased by $128 \%$ in LY and was higher than that of DH $(30.7 \%)$ compared with the control. Similarly, SOD and POD activities were lower in LY than in DH under control conditions. When plants were drought stressed, SOD and POD activities increased by $25.3 \%$ and $15.0 \%$ in LY, respectively, compared with the control, whereas only slightly increased in DH seedlings.

Through analyzing 2-DE gels, 17 and 32 DRPs spots were identified by using MALDI-TOF/TOF MS analysis in $\mathrm{DH}$ and LY genotypes, respectively. The position of the identified proteins is shown in Fig. 1 by their spot identities on the representative gel images, and a list of the identified proteins from DH and LY is shown in Table 1 Suppl. These proteins of theoretical/experimental $\mathrm{pI}$ and $\mathrm{MW}$, protein score, protein identity and accession number,
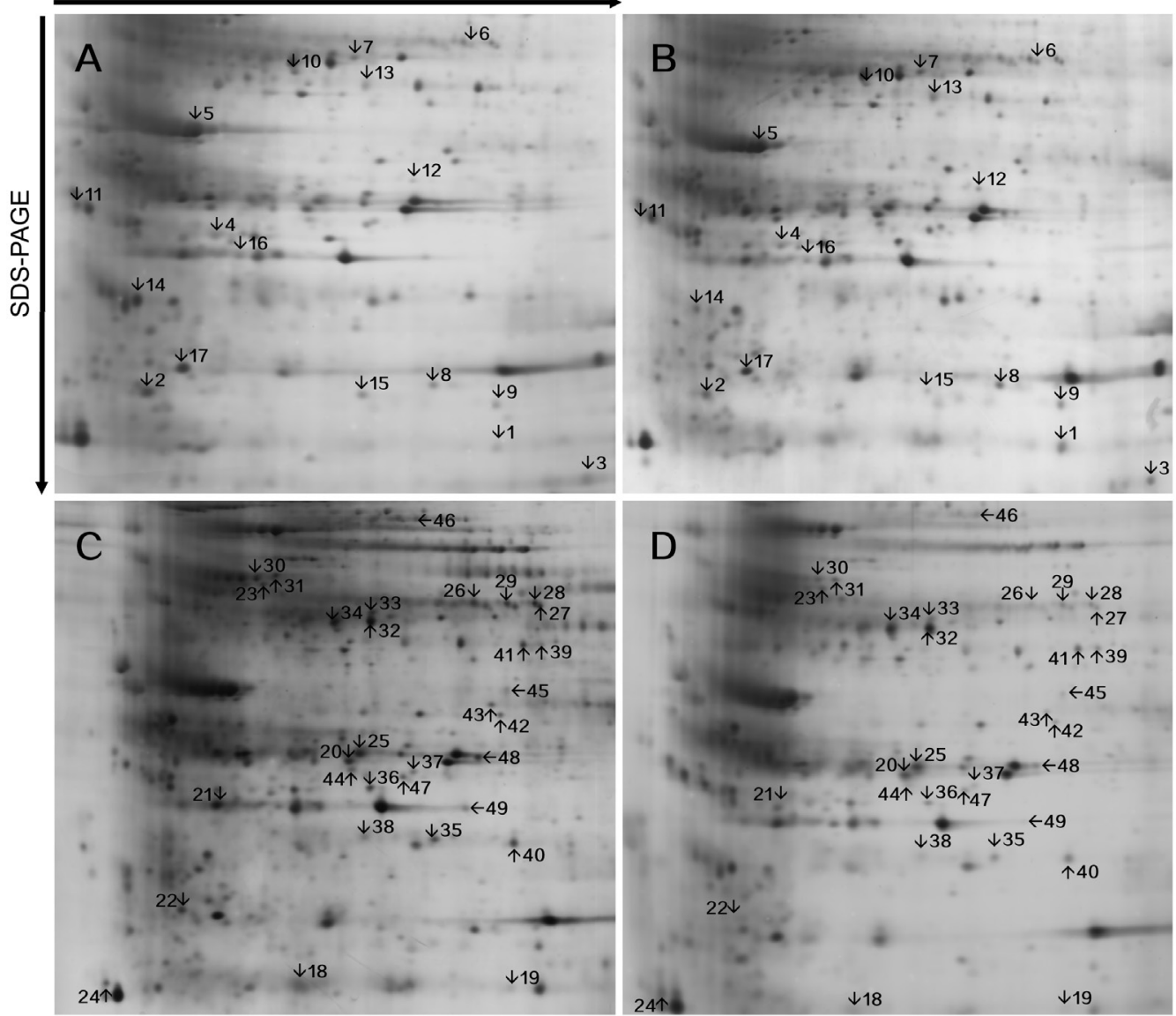

Fig. 1. Two-dimensional gel electrophoresis analysis of proteins extracted from Denghai 605 (DH) and Liyu 35 (LY) under control and drought stress conditions. $A$ and $B$ represent the control and drought stressed plants of DH, respectively; $C$ and $D$ represent the control and drought stressed plants of LY, respectively. These drought-responsive protein spots are marked with different numbers to specify their matched identities in Table 1 Suppl. This figure is a representative result from three biological replicates. 


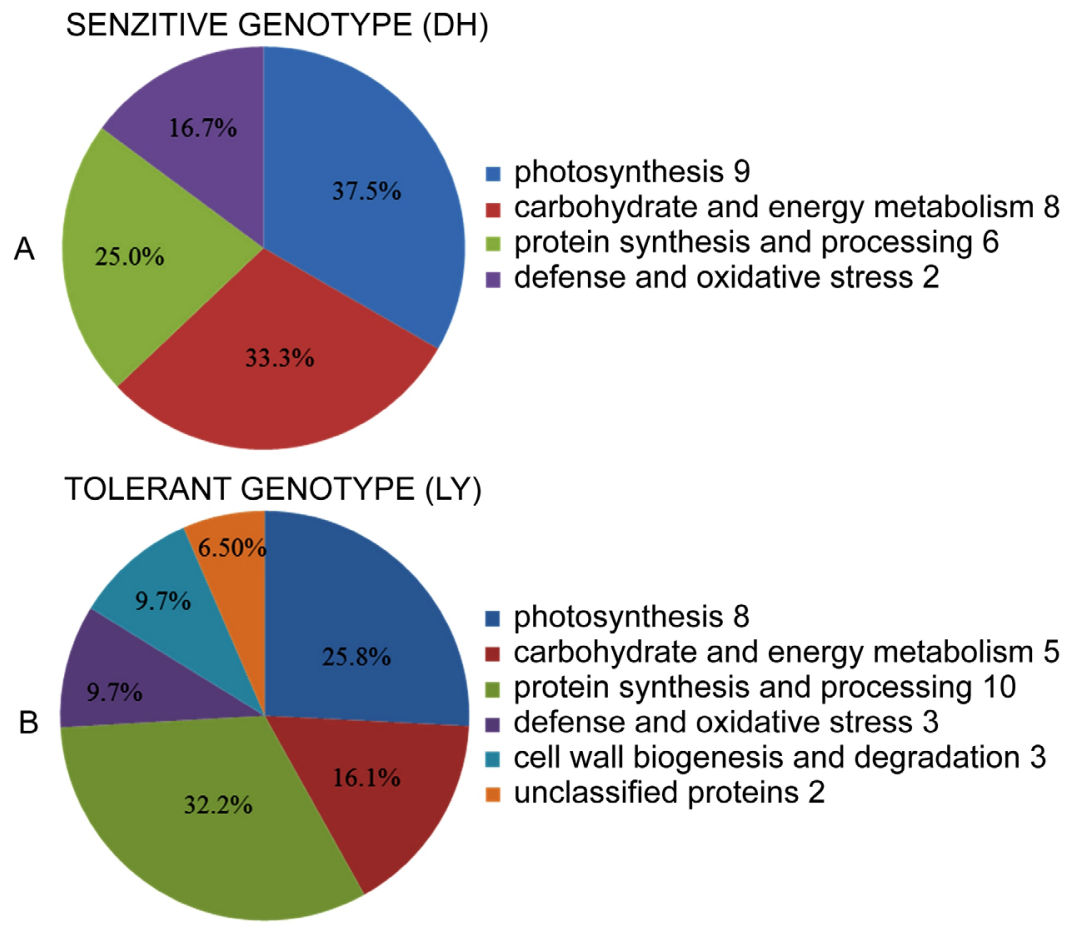

Fig. 2. Functional classification of drought-responsive proteins in Denghai 605 (DH) and Liyu 35 (LY) based on information deposited to the UniProt database (http://www.uniprot.org/).

the number of matched peptides, and the sequence of identified peptides are all shown in Table 2 Suppl.

Through the comparative analysis of these protein profiles, it was found that most proteins were common in both the genotypes, and similar proteins were identified at different spots in each genotype because similar proteins were spotted in multiple locations with differences in their isoelectric points and/or molecular weights on the 2-DE gel (Table 1 Suppl). The identification of multiple identities indicates that dehydration may cause post-translational modification(s) of the candidate proteins, isoforms, or members of multigene families. The mass spectra of some proteins detected in two or more distinct spots indicate the truncation of their $\mathrm{N}$-terminus and/or C-terminus.

Drought-responsive proteins in the two genotypes were further classified into four and six categories in DH and LY based on their main functional roles (Fig 2). These DRPs in LY were mainly categorized within protein synthesis and processing (32.2\%), carbohydrate and energy metabolism (16.1\%), and photosynthesis $(25.8 \%)$. Similarly, in DH, photosynthesis $(37.5 \%)$ and carbohydrate and energy metabolism $(33.3 \%)$ related proteins were dominant.

Interestingly, leaf proteins related to ATP synthesis and defense against oxidative stress pathway were downregulated in DH. However, a significant enrichment of proteins related to protein synthesis and processing, defense against oxidative stress was noted in LY (Table 1 Suppl). Several DRPs were expressed in DH and LY leaves in different ways, including germin-like protein (GLP) precursor, nucleoside diphosphate kinase 1 (NDPK) 1, endo-1,3-1,4-beta-D-glucanase (bGlu), NADdependent epimerase/dehydratase, retrotransposon protein
Ty1-copia subclass, opaque endosperm1, and glutathioneS-transferase (GST). In the following text, we will elucidate functional significance of some differentially abundant proteins in relation to tolerance to drought stress.

\section{Discussion}

One significant early symptom of water stress is a decreasing leaf RWC and leaf osmotic potential, representing variations in water potential, turgor potential, and osmotic adjustment in plant tissues (Jones 2007). In this study, a significant reduction occurred in leaf RWC and leaf osmotic potential of both the genotypes under drought stress, but the decreasing extent was higher in DH than in LY (Table 1). This imply that the LY genotype could absorb water more efficiently through a larger root system under drought stress. Similar results related to a decreased leaf RWC to drought stress responses were described in leaves of many plant species (Faghani et al. 2015, Chen et al. 2016, Król and Weidner 2017, Maheswari et al. 2016), but different results were reported in maize (Benesova et al. 2012, Yang et al. 2015) and peanut (Katam et al. 2016); leaf RWC of tolerant varieties decreased much more than that of the sensitive ones under drought stress.

Stomatal closure would retard plant growing capacity and potential biomass accumulation during drought period, as the closure of stomata affects photosynthetic efficiency and, subsequently, biomass production. Since leaves are the major photosynthetically active organs, pronounced decreases in leaf RWC and leaf osmotic potential will seriously affect photosynthesis and 
proteosynthesis, and decrease biomass production, which was in line with the reduced DWS, the rate of dry matter transformation, proline content and proteins (Table 1). These results suggest that drought stress caused stomatal closure in DH, decreasing water loss from leaves but impeding photosynthesis and proteosynthesis. In contrast, the lesser decrease in leaf RWC in LY probably kept these processes active. Understandably, it is difficult to uncover natural causality in plant stress reactions, but results found in this study imply that the differences in the drought response of the two analyzed maize genotypes might be connected primarily to their different sensitivities to stomatal closure under dehydration and secondarily to the different biosynthesis of proteins participating in photosynthesis and/or protective pathways. The LY genotype maintained active photosynthesis (at least under experimental conditions), enabling the synthesis of higher levels of various compounds/proteins that participate in cell protection/detoxification (Table 1 Suppl).

Root growth is a function of carbohydrates supplied by active organs of photosynthesis (Ogbonnaya et al. 1998), therefore, reductions in leaf RWC and osmotic potential would affect root growth, including length and volume of roots, DWR and ratio of root to shoot (Table 1). These results reveal that LY was less sensitive to drought stress, and had a strong lateral root system and a higher root to shoot ratio in comparison to $\mathrm{DH}$.

Numerous studies confirmed that environmental stresses could lift levels of reactive oxygen species (ROS), which may destroy cellular structures and ultimately kill cells. Moreover, MDA is widely used as a marker of oxidative lipid injury. In this study, content of MDA and proline, and activities of SOD and POD were enhanced by drought stress, especially for MDA and proline. Malondialdehyde content in DH leaves increased greatly, but was markedly lower in LY than in DH plants under drought stress (Table 1) indicating that much pronounced lipid peroxidation occurred in $\mathrm{DH}$ under stress conditions.

Both the maize cultivars had a similar proline content under control conditions, but proline content increased remarkably in LY and was greatly higher than that in DH plants under drought stress (Table 1). This may be one reason why accumulation of more proline and its involvement in osmotic adjustment, maintenance of cell turgor, and protection of different cell structures might be significantly improved in drought tolerance in LY maize. Previous reports also confirmed that moderate or severe drought affects biosynthesis and accumulation of proline (Anjum et al. 2017).

However, activities of SOD and POD were not significantly enhanced by drought stress in DH, whereas remarkable increased in drought-stressed LY seedlings as compared to the control. The results are consistent with the observations that the MDA level in DH increased more than in LY under drought stress (Table 1). It could be concluded that a significant accumulation of compatible osmolytes in tissues of drought tolerant LY plants and their powerful ROS scavenging roles indicate their roles against oxidative damage caused by drought stress. Previous studies proved that higher activities/levels of enzymatic and non-enzymatic antioxidants are important to induce drought tolerance (Mo et al. 2016, Anjum et al. 2017,). In short, morphology and physiological results suggest that the LY genotype could better tolerate drought stress compared to the DH.

Drought stress adversely affects photosynthesis process, alters photosynthesis metabolism, damages the structure of photosynthetic organs, and disorders antioxidant system (Souza et al. 2012, Marok et al. 2013,). In this study, the decrease in photosynthesis related proteins was similar to the previous reports, and the significant changes were observed in key photosynthetic proteins including the ribulose-1,5-bisphosphate carboxylase/oxygenase (RuBisCO) small subunit, oxygen-evolving enhancer protein (OEE) 1 and OEE2, oxygen evolving complex (OEC) subunit, chlorophyll $a / b$ binding protein (CBP) 6A, RuBisCO activase (RCA), plastocyanin and thylakoid lumenal proteins. The abundance of all these proteins decreased in the stressed plants in both genotypes except the RuBisCO small subunit, whereas its content increased during the stress treatment period (Table 1 Suppl). RuBisCO is a key enzyme involved in the first step of carbon fixation, a process which atmospheric $\mathrm{CO}_{2}$ is converted by plants to energy-rich molecules such as glucose (Spreitzer 1999). Under drought stress, RuBisCO might be excluded from chloroplasts into the cytoplasm through the formation of chloroplast protrusions and then be transported to vacuoles for a rapid degradation ( $\mathrm{He}$ et al. 2014), which may result in the increased abundance of the RuBisCO small subunit as was observed in this study (Table 1 Suppl). Contrary to our result, a decline in abundance of the RuBisCO small subunit was reported in Thellungiella halophila chloroplasts in response to drought stress (Chang et al. 2015).

In addition, OEEs can peripherally bind to photosystem (PS) II on the luminal side of the thylakoid membrane. Oxygen-evolving enhancer protein 1 plays important roles in maintaining the stability of PS II and oxygen evolution under drought stress (Parida and Jha 2010), whereas OEE2 is related to assembly of the PS II complex and protection of plants from drought stress (Sugihara et al. 2000). The decreased OEEs abundance suggest that the integrity and function of PS II were damaged in both the maize genotypes under drought stress. Additionally, OEC, known as the water-splitting complex, can react with water to produce free oxygen, provide electrons for PS II, and generate a transmembrane proton gradient during light reactions of photosynthesis (Kok et al. 1970), thus primary photodamage occurs at OEC (Takahashi and Murata 2008). The slightly decreased abundance of OEC suggest that it might be damaged by photoinhibition and that it provided fewer electrons for PS II. Chlorophyll $a / b$ binding protein 6A of PS I, which is an antenna protein, can capture photons and come into contact with pigments transferring excitation energy to reaction centers and thereby increasing NADPH from $\mathrm{NADP}^{+}$generation (Kok et al. 1970). In this study, CBP 6A decreased by drought stress in DH (Table 1 Suppl), which might reduce electron transport and provide less $\mathrm{NADPH}$ for carbon fixation. RuBisCO activase is a 
molecular chaperon controling switching RuBisCO from an inactive to active conformation (Spreitzer and Salvucci 2002). In the current study, RCA was downregulated under drought stress in LY suggesting that RCA might reduce the possibility of its own attachment to thylakoid membranes, thus damaging the activity of RuBisCO and decreasing thylakoid lumenal $19 \mathrm{kDa}$ and $17.4 \mathrm{kDa}$ proteins under drought stress (Table 1 Suppl). Contrary to the results found in this study, an increase in abundance of RCA was reported in maize in response to drought stress (Benesova et al. 2012). However, overexpressing RCA showed a decreased photosynthetic $\mathrm{CO}_{2}$ assimilation due to decreased $\mathrm{RuBisCO}$ content in transgenic rice plants (Fukayama et al. 2012). Thus, drought stress increased photoinhibition primary by disturbing the structure of PS II and damaging the integrity of the thylakoid membrane resulting in a rapid decline in the activity of PS II.

Three identical proteins of DRPs in leaves of the two maize genotypes were involved in synthesis and processing proteins, i.e., $50 \mathrm{~S}$ ribosomal protein $\mathrm{L} 1$, proteasome subunit, peptidyl-prolyl cis-trans isomerase (PPI). The amount of the PPI protein was downregulated in $\mathrm{DH}$, whereas upregulated in LY under stress conditions (Table 1 Suppl). Peptidyl-prolyl cis-trans isomerases, a group of cyclophilin (CYP)-type proteins, are involved in protein folding by interconverting cis- and trans-rotamers of the peptidyl prolyl amide bond of peptides and are present in a wide range of organisms from archaea and bacteria to plants and animals (Kumari et al. 2013). The chaperone-like activity of PPIs and their role in the ratelimiting step of protein folding by peptidyl prolyl bond isomerization is associated with their involvement in stress responses (Brandts et al. 1975). The expression levels of several $O s C Y P$ s are increased by abiotic stresses, such as desiccation and salt stress (Ahn et al. 2010), indicating a critical role of $O s C Y P s$ during stress conditions. In this study, the PPI was strongly downregulated in DH after a drought period but upregulated in LY, which indicates that LY was of a stronger native drought tolerance.

It is well known that abiotic stresses could induce denaturation and aggregation of cellular proteins. In this study, the content of proteases increased in the stressed plants of both the genotypes, which imply a higher rate of damaged/unnecessary protein degradation occurred under stress, indicating the need for sensitive and selective regulation of both protein synthesis and degradation. Similarly, Aranjuelo et al. (2011) found an upregulation of one of proteasome subunits in the leaves of alfalfa upon its subjection to a low water supply, and Zhao et al. (2016) observed the promotion of protein hydrolysis in maize leaves subjected to drought stress.

Carbohydrate and energy metabolism-related proteins like glyceraldehyde-3-phosphate dehydrogenase (GAPDH), malate dehydrogenase 2 and NDPK 1 increased in $\mathrm{DH}$, but GAPDH was abundant in LY. In this proteomic analysis, at least two isoforms of GAPDH (GAPDH1 and 2) were clearly induced under drought stress (Table 1 Suppl) and participated in carbon fixation. Indeed, GAPDH is involved in photosynthesis and carbon metabolism via functional analysis. The GAPDH is a key enzyme catalyzing conversion of glycerate-3-phosphate to glyceraldehyde-3phosphate and interacts with ATP and NADPH. Glycerate3-phosphate can accept electrons from NADPH to protect PS II by preventing the ROS-induced deceleration of repair, whereas glyceraldehyde-3-phosphate is used to synthesize starch in chloroplasts (Chang et al. 2015). In this study, a higher abundance of GAPDH in LY suggests the early acceleration of the glycolytic pathway upon drought stress. Thus, in LY, the photosynthesis mechanism seems less affected as is evident from the abundance of more photooxidation protective proteins, such as SOD and GST for protecting photosystems I and II, which ensures electron flow to $\mathrm{NADP}^{+}$and preventing oxidative stress. This result is also consistent with a decreased abundance of ATP synthase in DH. An ATP synthase is an important enzyme that provides energy for the cell through ATP synthesis by proton-motive force (Tikhonov 2013). In this study, ATP synthase was detected in a lower abundance in DH suggesting that ATP synthesis process in this genotype was significantly disrupted by drought stress. Furthermore, it indicates that ATP synthase could not meet energy demand in the cellular process and alleviate water deficit stress by increasing ATP supply to meet increasing stressrelated energy demand. The NDPK, one key metabolic enzyme that maintains balance between cellular ATP and other nucleoside triphosphates increased in DH. Previous studies showed that NDPKs play a significant role in the signal transduction pathways of root response to heat stress (Tang et al. 2008). The upregulation of NDPKs amount has been reported in response to drought, heat, and salt stresses (Hajheidari et al. 2005, Dooki et al. 2006, Lee et al. 2007). However, in this study, it was upregulated by drought stress in DH but not in LY.

When the maize seedlings grew under drought, the main component of the apoplast and the cell wall were significantly affected. Several cell wall-related proteins involved in cell wall biogenesis and degradation were found in LY. The endo-1,3-1,4-beta-D-glucanase (bGlu) was induced in LY under drought stress, whereas no protein was detected in DH. The bGlu catalyzes the hydrolysis of beta-1,3-glucans, which serve as major components of primary cell walls in many plant tissues and are referred as pathogenesis-related proteins (Faghani et al. 2015). Notably, bGlu was reported to play roles in antifungal defenses (Fujimori et al. 2016), and it could defense against drought stress (Budak et al. 2013, Król and Weidner 2017) in many plants. An increase in enzyme activity and mRNA of bGlu was reported in clover leaves under drought stress (Lee et al. 2008). It can be assumed that more abundant bGlu in leaves of drought stressed plants would strengthen the cell wall and assist plants to resist against stressinduced damage.

Interestingly, the levels of the proteins representing Mn-SOD and glutathione-S-transferase 3 were upregulated in LY, whereas DH was featured by a downregulation of $\mathrm{Cu} / \mathrm{Zn}$ SOD and a GLP precursor (Table 1 Suppl). The association between the levels/activities of antioxidant enzymes and plant drought tolerance has been observed in wheat (Loggini et al. 1999, Lascano et al. 2001) and rice (Guo et al. 2006). Manganese-SOD is the principal 
scavenger of a superoxide in mitochondria, thus its upregulation in LY may provide the dismutation role of the superoxide radical to $\mathrm{H}_{2} \mathrm{O}_{2}$ and oxygen in mitochondria. It appears that the multi component antioxidant systems may take part in ROS scavenging and maintaining a higher drought tolerance in LY. Similarly, in this study, in agreement with the change in activity of SOD, an increased Mn-SOD protein abundance in response to drought stress was observed in the drought-tolerant LY genotype by 2-DE.

Additionally, GSTs are abundant proteins encoded by a highly divergent gene family and have protective functions such as the detoxification of herbicides and the reduction of organic $\mathrm{H}_{2} \mathrm{O}_{2}$ during oxidative stress. As observed in previous studies, GSTs are induced by drought stress in maize (Hu et al. 2011, Liu et al. 2012), wheat (Caruso et al. 2009, Faghani et al. 2015), and rice (Lee et al. 2007). Other studies, however, showed that GSTs are reduced under drought stress in poplar roots (Plomion et al. 2006). The present study shows that GST was significantly induced under drought stress in the tolerant LY genotype but not found in $\mathrm{DH}$, and the upregulation of GST in LY might protect the cell membrane from oxidative damage and maintain cellular redox homeostasis (Gill and Tuteja 2010).

The GLPs are involved in diverse processes including germination, development, and response to biotic and abiotic stresses (Davidson et al. 2009). In some plants, such as wheat, GLPs possess a SOD activity (Faghani et al. 2015). This study discovered that GLP decreased by drought stress in the sensitive $\mathrm{DH}$ genotype, and it is inconsistent with the report that an increased abundance of GLP was found in barley in response to drought stress (Kausar et al. 2013). In general, proteomic studies performed in drought-tolerant and drought-sensitive cultivars of maize (Benesova et al. 2012), wheat (Hajheidari et al. 2007, Faghani et al. 2015) and barley (Kausar et al. 2013) showed that these cultivars differ with respect to the changes in the abundance of SOD, GST, and GLP, which, together with the results in this study, clearly highlights the important role of these proteins in ameliorating tolerance to drought stress.

In summary, for practical reasons, numerous physiological responses and protein molecular dynamics could not be dynamically monitored under drought stress, thus the physiological bases and molecular mechanism of drought resistance could not be investigated comprehensively. Consequently, the findings on the physiological bases and molecular mechanism of drought resistance should be confirmed in future studies.

\section{References}

Ahn, J.C., Kim, D.W., You, Y.N., Seok, M.S., Park, J.M., Hwang, H., Kim, B.G., Luan, S., Park, H.S., Cho, H.S.: Classification of rice (Oryza sativa I. japonica nipponbare) immunophilins (FKBPs, CYPs) and expression patterns under water stress. BMC Plant Biol. 10: 1-22, 2010.

Anjum, S.A., Ashraf, U., Tanveer, M., Khan, I., Hussain, S., Shahzad, B., Zohaib, A., Abbas, F., Saleem, M.F., Ali, I.,
Wang, L.C.: Drought induced changes in growth, osmolyte accumulation and antioxidant metabolism of three maize hybrids. - Front. Plant Sci. 8: 69, 2017.

Aranjuelo, I., Molero, G., Erice, G., Avice, J.C., Nogues, S.: Plant physiology and proteomics reveals the leaf response to drought in alfalfa (Medicago sativa L.). - J. exp. Bot. 62: 111123, 2011.

Ashraf, M.: Inducing drought tolerance in plants: Recent advances. - Biotechnol. Adv. 28: 169-183, 2010.

Bates, L.S., Waldren, R.P., Teare, I.D.: Rapid determination of free proline for water-stress studies. - Plant Soil. 39: 205-207, 1973.

Beauchamp, C., Fridovich, I.: Superoxide dismutase: Improved assays and an assay applicable to acrylamide gels. - Anal. Biochem. 44: 276-287, 1971.

Benesova, M., Hola, D., Fischer, L., Jedelsky, P.L., Hnilicka, F., Wilhelmova, N., Rothova, O., Kocova, M., Prochazkova, D., Honnerova, J., Fridrichova, L., Hnilickova, H.: The physiology and proteomics of drought tolerance in maize: early stomatal closure as a cause of lower tolerance to shortterm dehydration? - PLoS ONE. 7: e38017, 2012.

Boyer, J.S.: Grain yields with limited water. - J. exp. Bot. 55: 2385-2394, 2004.

Brandts, J.F., Halvorson, H.R., Brennan, M.: Consideration of the possibility that the slow step in protein denaturation reactions is due to cis-trans isomerism of proline residues. Biochemistry 14: 4953-4963, 1975.

Budak, H., Akpinar, B.A., Unver, T., Turktas, M.: Proteome changes in wild and modern wheat leaves upon drought stress by two-dimensional electrophoresis and nanoLC-ESI-MS/ MS. - Plant mol. Biol. 83: 89-103, 2013.

Caruso, G., Cavaliere, C., Foglia, P., Gubbiotti, R., Samperi, R., Laganà, A.: Analysis of drought responsive proteins in wheat (Triticum durum) by 2D-PAGE and MALDI-TOF mass spectrometry. - Plant Sci. 177: 570-576, 2009.

Chang, L.L., Guo, A.P., Jin, X., Yang, Q., Wang, D., Sun, Y., Huang, Q.X., Wang, L.M., Peng, C.Z., Wang, X.C.: The beta subunit of glyceraldehyde 3-phosphate dehydrogenase is an important factor for maintaining photosynthesis and plant development under salt stress-Based on an integrative analysis of the structural, physiological and proteomic changes in chloroplasts in Thellungiella halophila. - Plant Sci. 236: 223 238, 2015.

Chen, D.Q., Wang, S.W., Cao, B.B., Cao, D., Leng, G.H., Li, H.B., Yin, L.N., Shan, L., Deng, X.P.: Genotypic variation in growth and physiological response to drought stress and re-watering reveals the critical role of recovery in drought adaptation in maize seedlings. - Front. Plant Sci. 6: 1241, 2016.

Davidson, R.M., Reeves, P.A., Manosalva, P.M., Leach, J.E.: Germins: A diverse protein family important for crop improvement. - Plant Sci. 177: 499-510, 2009.

Deeba, F., Pandey, A.K., Ranjan, S., Mishra, A., Singh, R., Sharma, Y.K., Shirke, P.A., Pandey, V.: Physiological and proteomic responses of cotton (Gossypium herbaceum L.) to drought stress. - Plant Physiol. Biochem. 53: 6-18, 2012.

Dipierro, S., Leonardis, S.D.: The ascorbate system and lipid peroxidation in stored potato (Solanum tuberosum L. ) tubers. - J. exp. Bot. 48: 779 -783, 1997.

Dooki, A.D., Mayer-Posner, F.J., Askari, H., Zaiee, A.A., Salekdeh, G.H.: Proteomic responses of rice young panicles to salinity. - Proteomics 6: 6498-6507, 2006.

Faghani, E., Gharechahi, J., Komatsu, S., Mirzaei, M., Khavarinejad, R.A., Najafi, F., Farsad, L.K., Salekdeh, G.H.: Comparative physiology and proteomic analysis of two wheat genotypes contrasting in drought tolerance. - J. Proteom. 114: 
$1-15,2015$.

Farooq, M., Wahid, A., Kobayashi, N., Fujita, D., Basra, S.M.A.: Plant drought stress: effects, mechanisms and management. Agron. Sustain. Dev. 29: 185-212, 2009.

Fujimori, N., Enoki, S., Suzuki, A., Naznin, H.A., Shimizu, M., Suzuki, S.: Grape apoplasmic $\beta$-1,3-glucanase confers fungal disease resistance in Arabidopsis. - Sci. Hort. 200: 105-110, 2016.

Fukayama, H., Ueguchi, C., Nishikawa, K., Katoh, N., Ishikawa, C., Masumoto, C., Hatanaka, T., Misoo, S.: Overexpression of rubisco activase decreases the photosynthetic $\mathrm{CO}_{2}$ assimilation rate by reducing rubisco content in rice leaves. Plant Cell Physiol. 53: 976-986, 2012.

Gill, S.S., Tuteja, N.: Reactive oxygen species and antioxidant machinery in abiotic stress tolerance in crop plants. - Plant Physiol. Biochem. 48: 909-930, 2010.

Guo, Z., Ou, W., Lu, S., Zhong, Q.: Differential responses of antioxidative system to chilling and drought in four rice cultivars differing in sensitivity. - Plant Physiol. Biochem. 44: 828-836, 2006.

Hajheidari, M., Eivazi, A., Buchanan, B.B., Wong, J.H., Majidi, I.: Proteomics uncovers a role for redox in drought tolerance in wheat. - J. Proteome Res. 6: 1451-1460, 2007.

Hajheidari, M., Abdollahian-Noghabi, M., Askari, H., Heidari, M., Sadeghian, S.Y., Ober, E.S., Salekdeh, G.H.: Proteome analysis of sugar beet leaves under drought stress. - Proteomics 5: 950-960, 2005.

Hammerschmidt, R., Nuckles, E.M., Kuć, J.: Association of enhanced peroxidase activity with induced systemic resistance of cucumber to Colletotrichum lagenarium. - Physiol. Plant Pathol. 20: 73-82, 1982.

He, Y., Yu, C.L., Zhou, L., Chen, Y., Liu, A., Jin, J.H., Hong, J., Qi, Y.H., Jiang, D.: Rubisco decrease is involved in chloroplast protrusion and Rubisco-containing body formation in soybean (Glycine max.) under salt stress. - Plant Physiol. Biochem. 74: 118-124, 2014.

Hu, X.L., Lu, M.H., Li, C.H., Liu, T.X., Wang, W., Wu, J.Y., Tai, F.J., Li, X., Zhang, J.: Differential expression of proteins in maize roots in response to abscisic acid and drought. - Acta Physiol. Plant. 33: 2437-2446, 2011.

Jones, H.G.: Monitoring plant and soil water status: established and novel methods revisited and their relevance to studies of drought tolerance. - J. exp. Bot. 58: 119-130, 2007.

Kakumanu, A., Ambavaram, M.M., Klumas, C., Krishnan, A., Batlang, U., Myers, E., Grene, R., Pereira, A.: Effects of drought on gene expression in maize reproductive and leaf meristem tissue revealed by RNA-Seq. - Plant Physiol. 160: 846-867, 2012.

Katam, R., Sakata, K., Suravajhala, P., Pechan, T., Kambiranda, D.M., Naik, K.S., Guo, B., Basha, S.M.: Comparative leaf proteomics of drought-tolerant and -susceptible peanut in response to water stress. - J. Proteom. 143: 209-226, 2016.

Kausar, R., Arshad, M., Shahzad, A., Komatsu, S.: Proteomics analysis of sensitive and tolerant barley genotypes under drought stress. - Amino Acids. 44: 345-359, 2013.

Kok, B., Forbush, B., McGloin, M.: Cooperation of charges in photosynthetic $\mathrm{O}_{2}$ evolution-I. A linear four step mechanism. - Photochem. Photobiol. 11: 457-475, 1970.

Król, A., Weidner, S.: Changes in the proteome of grapevine leaves (Vitis vinifera L.) during long-term drought stress. - J. Plant Physiol. 211: 114-126, 2017.

Kumari, S., Roy, S., Singh, P., Singla-Pareek, S.L., Pareek, A.: Cyclophilins: proteins in search of function. - Plant Signal. Behav. 8: e22734, 2013.

Lascano, H.R., Antonicelli, G.E., Luna, C.M., Melchiorre, M.N., Gómez, L.D., Racca, R.W., Trippi, V.S., Casano, L.M.:
Antioxidant system response of different wheat cultivars under drought: field and in vitro studies. - Funct. Plant Biol. 28: 1095-1102, 2001.

Lee, B.R., Jung, W.J., Lee, B.H., Avice, J.C., Ourry, A., Kim, T.H.: Kinetics of drought-induced pathogenesis-related proteins and its physiological significance in white clover leaves. - Physiol. Plant. 132: 329-337, 2008.

Lee, D.G., Ahsan, N., Lee, S.H., Kang, K.Y., Bahk, J.D., Lee, I.J., Lee, B.H.: A proteomic approach in analyzing heatresponsive proteins in rice leaves. - Proteomics 7: 3369-3383, 2007.

Liu, T.X., Zhang, L., Yuan, Z.L., Hu, X.L., Lu, M.H., Wang, W., Wang, Y.: Identification of proteins regulated by ABA in response to combined drought and heat stress in maize roots. - Acta Physiol. Plant. 35: 501-513, 2012.

Loggini, B., Scartazza, A., Brugnoli, E., Navari-Izzo, F.: Antioxidative defense system, pigment composition, and photosynthetic efficiency in two wheat cultivars subjected to drought. - Plant Physiol. 119: 1091-1099, 1999.

Mahajan, S., Tuteja, N.: Cold, salinity and drought stresses: an overview. - Arch. Biochem. Biophys. 444: 139-158, 2005

Maheswari, M., Tekula, V.L., Yellisetty, V., Sarkar, B., Yadav, S.K., Singh, J., G, S.B., Kumar, A., Amirineni, S., Narayana, J., Maddi, V.: Functional mechanisms of drought tolerance in maize through phenotyping and genotyping under well watered and water stressed conditions. - Eur. J. Agron. 79: 43-57, 2016.

Marok, M.A., Tarrago, L., Ksas, B., Henri, P., Abrous-Belbachir, O., Havaux, M., Rey, P.: A drought-sensitive barley variety displays oxidative stress and strongly increased contents in low-molecular weight antioxidant compounds during water deficit compared to a tolerant variety. - J. Plant Physiol. 170: 633-645, 2013.

Mo, Y.L., Yang, R.P., Liu, L.H., Gu, X.R., Yang, X.Z., Wang, Y.Q., Zhang, X., Li, H.: Growth, photosynthesis and adaptive responses of wild and domesticated watermelon genotypes to drought stress and subsequent re-watering. - Plant Growth Regul. 79: 229-241, 2016.

Nuccio, M.L., Wu, J., Mowers, R., Zhou, H.P., Meghji, M., Primavesi, L.F., Paul, M.J., Chen, X., Gao, Y., Haque, E., Basu, S.S., Lagrimini, L.M.: Expression of trehalose-6phosphate phosphatase in maize ears improves yield in wellwatered and drought conditions. - Nat. Biotechnol. 33: 862$869,2015$.

Ogbonnaya, C.I., Nwalozie, M.C., Roy-Macauley, H., Annerose, D.J.M.: Growth and water relations of Kenaf (Hibiscus cannabinus L.) under water deficit on a sandy soil. - Ind. Crops. Products. 8: 65-76, 1998.

Parida, A.K., Jha, B.: Salt tolerance mechanisms in mangroves: a review. - Trees 24: 199-217, 2010.

Plomion, C., Lalanne, C., Claverol, S., Meddour, H., Kohler, A., Bogeat-Triboulot, M.B., Barre, A., Le Provost, G., Dumazet, H., Jacob, D., Bastien, C., Dreyer, E., de Daruvar, A., Guehl, J.M., Schmitter, J.M., Martin, F., Bonneu, M.: Mapping the proteome of poplar and application to the discovery of drought-stress responsive proteins. - Proteomics 6: 65096527,2006

Ribaut, J.M., Jiang, C., Gonzalez-de-Leon, D., Edmeades, G.O., Hoisington, D.A.: Identification of quantitative trait loci under drought conditions in tropical maize. - Tag Theor. Appl. Genet. 94: 887-896, 1997.

Souza, T.C., César, M.P., Castro, E.M., Albuquerque, P.E.P., Marabesi, M.A.: The influence of ABA on water relation, photosynthesis parameters, and chlorophyll fluorescence under drought conditions in two maize hybrids with contrasting drought resistance. - Acta Physiol. Plant. 35: 515- 
$527,2012$.

Spreitzer, R.J.: Questions about the complexity of chloroplast ribulose-1,5-bisphosphate carboxylase/oxygenase. Photosynth. Res. 60: 29-42, 1999.

Spreitzer, R.J., Salvucci, M.E.: Rubisco: structure, regulatory interactions, and possibilities for a better enzyme. - Annu. Rev. Plant Biol. 53: 449-475, 2002.

Sugihara, K., Hanagata, N., Dubinsky, Z., Baba, S., Karube, I.: Molecular characterization of cDNA encoding oxygen evolving enhancer protein 1 increased by salt treatment in the mangrove Bruguiera gymnorrhiza. - Plant Cell Physiol. 41: 1279-1285, 2000.

Takahashi, S., Murata, N.: How do environmental stresses accelerate photoinhibition? - Trends Plant Sci. 13: 178-182, 2008.

Tang, L., Kim, M.D., Yang, K.S., Kwon, S.Y., Kim, S.H., Kim, J.S., Yun, D.J., Kwak, S.S., Lee, H.S.: Enhanced tolerance of transgenic potato plants overexpressing nucleoside diphosphate kinase 2 against multiple environmental stresses. - Transgenic. Res. 17: 705-715, 2008.

Thatcher, S.R., Danilevskaya, O.N., Meng, X., Beatty, M., Zastrow-Hayes, G., Harris, C., Van Allen, B., Habben, J., Li, B.: Genome-wide analysis of alternative splicing during development and drought stress in maize. - Plant Physiol. 170: 586-599, 2016.

Tikhonov, A.N.: pH-Dependent regulation of electron transport and ATP synthesis in chloroplasts. - Photosynth. Res. 116: 511-534, 2013.

Urban, M.O., Vašek, J., Klíma, M., Krtková, J., Kosová, K., Prášil, I.T., Vítámvás, P.: Proteomic and physiological approach reveals drought-induced changes in rapeseeds: Water-saver and water-spender strategy. - J. Proteom. 152:
188-205, 2016.

Vítámvás, P., Urban, M.O., Škodáček, Z., Kosová, K., Pitelková, I., Vítámvás, J., Renaut, J., Prášil, I.T.: Quantitative analysis of proteome extracted from barley crowns grown under different drought conditions. - Front. Plant Sci. 6: 479, 2015.

Wang, W., Vignani, R., Scali, M., Cresti, M.: A universal and rapid protocol for protein extraction from recalcitrant plant tissues for proteomic analysis. - Electrophoresis 27: 27822786, 2006.

Wang, Z., Wang, Z., Shi, L., Wang, L., Xu, F.: Proteomic alterations of Brassica napus root in response to boron deficiency. - Plant Mol.Biol. 74: 265-278, 2010.

Xie, H., Yang, D.H., Yao, H., Bai, G., Zhang, Y.H., Xiao, B.G.: iTRAQ-based quantitative proteomic analysis reveals proteomic changes in leaves of cultivated tobacco (Nicotiana tabacum) in response to drought stress. - Biochem. Biophy. Res. Commun. 469: 768-775, 2016.

Xu, J., Yuan, Y.B., Xu, Y.B., Zhang, G.Y., Guo, X.S., Wu, F.K., Wang, Q., Rong, T.Z., Pan, G.T., Cao, M.J., Tang, Q.L., Gao, S.B., Liu, Y.X., Wang, J., Lan, H., Lu, Y.L.: Identification of candidate genes for drought tolerance by whole-genome resequencing in maize. - BMC Plant Biol. 14: 1-15, 2014.

Yang, L.M., Fountain, J.C., Wang, H., Ni, X.Z., Ji, P.S., Lee, R.D., Kemerait, R.C., Scully, B.T., Guo, B.Z.: Stress sensitivity is associated with differential accumulation of reactive oxygen and nitrogen species in maize genotypes with contrasting levels of drought tolerance. - Int. J. Mol. Sci. 16: 2479124819, 2015.

Zhao, F., Zhang, D., Zhao, Y., Wang, W., Yang, H., Tai, F., Li, C., Hu, X.: The difference of physiological andpProteomic changes in maize leaves adaptation to drought, heat, and combined both stresses. - Front. Plant Sci. 7: 1471, 2016. 